\title{
Percutaneous treatment of a aorto-caval fistula in a old high risk patient
}

\author{
Antonio Rapacciuolo ${ }^{1}$, Maria Carmen De Angelis ${ }^{1}$, Elisa di Pietro ${ }^{1}$, Roberto Puglia ${ }^{1}$, Ettore Di Tommaso ${ }^{1 *}$, \\ Danilo Ruggiero', Bruno Amato², Gabriele lannelli ${ }^{1}$ \\ From XXV National Congress of the Italian Society of Geriatric Surgery \\ Padova, Italy. 10-11 May 2012
}

\begin{abstract}
Background: To remark the feasibility of endovascular treatment of an aorto-caval fistula in a old high risk patient with "hostile" abdomen for previous surgeries.

Methods: In September 2009 a 81-years-old patient was admitted in emergency at our department because of abdominal pain and massive oedema of the lower extremities associated to dyspnoea (New York Heart Association (NYHA) functional class III). A CT scan showed an aorto-caval fistula involving the abdominal aorta below the renal arteries. This abnormal communication was likely due to the previous abdominal surgeries, was complicated by occlusion of the inferior vena cava at the diaphragm and was responsible for the massive oedema of the lower extremities. Because of unstable conditions and hostile abdomen the patient was considered unfit for conventional surgery and an endovascular approach was planned. After unsuccessful attempt by positioning of an Amplatzer vascular ring into the fistula, a Medtronic covered stent-grafts were implanted from the renal arteries to the both common iliac arteries. The patient had an impressive improvement characterized by a $18 \mathrm{Kg}$ weight loss and a complete restoration of the functional capacity (from NYHA class III to NYHA class I) associated to a complete resolution of the lower extremities oedema as confirmed at the a month-CT-scan.
\end{abstract}

Conclusion: Endovascular surgery of aorto-caval fistula represents a good option in alternative to conventional surgery mostly in old high risk patient.

\section{Methods}

In the year 2002 a 74 years-old man was diagnosed with retroperitoneal fibrosis which had caused bilateral ureteral obstruction. The right kidney function was successfully restored by stent placement.

In the year 2003 the patient was subjected to left nephrostomy to restore kidney function but the treatment was complicated by capsular haematoma that was surgically removed. Thereafter the left kidney was not functioning anymore.

In October 2008 the patient was admitted to the emergency room because of small bowel sub-obstruction and underwent a surgical operation in order to remove the

\footnotetext{
* Correspondence: etditom@tin.it

'Department of Clinical Medicine, Cardiovascular and Immunological

Sciences, Federico II University of Naples, Italy

Full list of author information is available at the end of the article
}

fibrotic adherences causing the symptoms. Despite the previous diagnosis, he had not been specifically treated for the retroperitoneal fibrosis.

In September 2009 the patient arrived at our observation for the first time. He was admitted in the emergency room because of abdominal pain and massive oedema of the lower extremities associated to dyspnoea.

On arrival at our Department, the patient related dyspnoea, New York Heart Association (NYHA) functional class III. He was awake and conversant. The pulse was 88 beats per minute and the blood pressure 150/80. The skin was cool and dry. On physical examination, his oxygen saturation was $96 \%$ while he was breathing room air. He had massive oedema of both lower extremities.

A CT scan was performed that evidenced retroperitoneal fibrosis (figure 1A) as well as an aorto-caval fistula involving the abdominal aorta below the renal arteries

\section{Biomed Central}




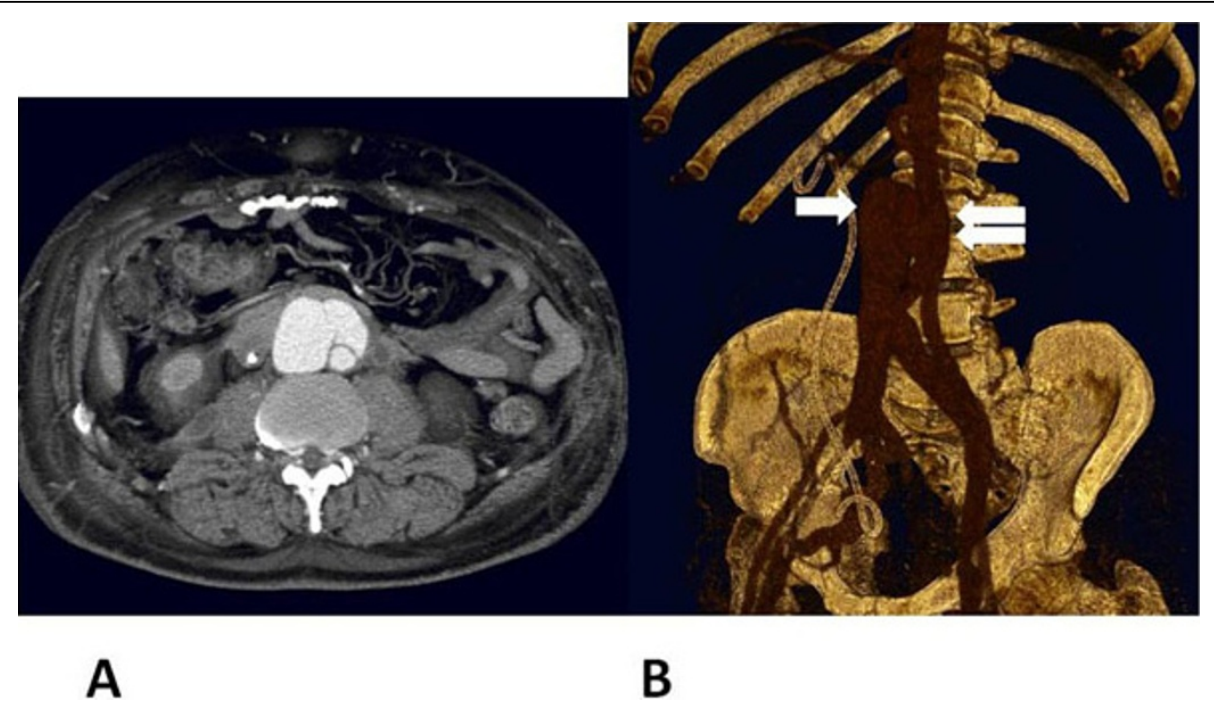

Figure 1 A Retroperitoneal fibrosis demonstrated at CT scan B Aorto-caval fistula originating from the abdominal aorta below the renal arteries (double arrow). The inferior vena cava (arrow) was completely occluded few centimetres above the communication with the aorta.

(figure 1B). This abnormal communication was likely due to the previous abdominal surgeries which had caused a hyatrogenic fistulous aorto-caval shunt. The inferior vena cava was completely occluded few centimetres above the communication with the aorta (figure 1B). This preserved the patient from massive pulmonary hyperafflux and was responsible for the massive oedema of the lower extremities.

The majority of Aorto-Caval Fistulas occur spontaneously, with most resulting from the rupture of an existing AAA into the vena cava or as result from iatrogenic injuries occurring during peripheral angiography, surgery or other potential etiologies [1].

Symptomatic ACFs have traditionally been repaired using open surgical techniques. These procedures can be technically challenging, with significant intraoperative blood loss and high operative morbidity and mortality rates approaching 30\% [2].

The hostile abdomen with age and heart failure are a well recognized high-risk criteria for conventional surgery leading to a minimally invasive approach.

Since the patient had a surgically "hostile abdomen" due to retroperitoneal fibrosis, we decided to percutaneously treat the aorto-caval communication [3]. We selectively cannulated the aorto-caval fistula originating in the anterior wall of the aorta with a 7 FR guiding catheter and implanted an AMPLATZER ${ }^{\circledR}$ Vascular Plug II (AGA Medical Corporation), which is a unique multi-segmented, multi-layered design nitinol plug that significantly reduces occlusion time for transcatheter embolization procedures. The three adjustable lobes of the AMPLATZER Vascular Plug II are designed for enhanced conformability to vessel landing zones. We obtained a good angiographic result with almost complete abolishment of the shunt. In 3 days the patient had a $9 \mathrm{Kg}$ weight loss associated to a significant reduction of the lower extremities oedema and of the dyspnoea.

One month later the patient was regaining weight and there was a worsening of the symptoms. A new CT scan was performed which showed recurrence of the aortocaval communication which was likely due to an additional fistula that was not closed with the initial procedure. The CT scan also showed the Amplatzer vascular plug still in correct position (fig. 2).

We therefore performed a new aortogram confirming the recurrence of the aorto-caval communication with the major shunt originating in the posterolateral left wall of the aorta. In order to obtain a complete occlusion of the aorto-caval communication, we decided to implant an aortic prosthesis Talent (Medtronic). The TalentTM Abdominal Stent Graft is designed to treat abdominal aortic aneurysms using a minimally invasive procedure called endovascular stent grafting. It is used to reinforce the weakened wall of the vessel to prevent the aneurysm from rupturing. The Talent Stent Graft is a woven polyester tube supported by a tubular metal web that expands to a pre-established diameter when placed in the artery $[4,5]$.

We first implanted an aortic stent graft that covered the abdominal aorta starting below the renal arteries and landing right before the aortic bifurcation. However, a residual shunt was still present. This residual fistulous communication was completely abolished by implanting an additional Talent device which would cover the abdominal aorta and both the iliac arteries. The patient had an impressive clinical course characterized by a $18 \mathrm{Kg}$ weight loss and a 


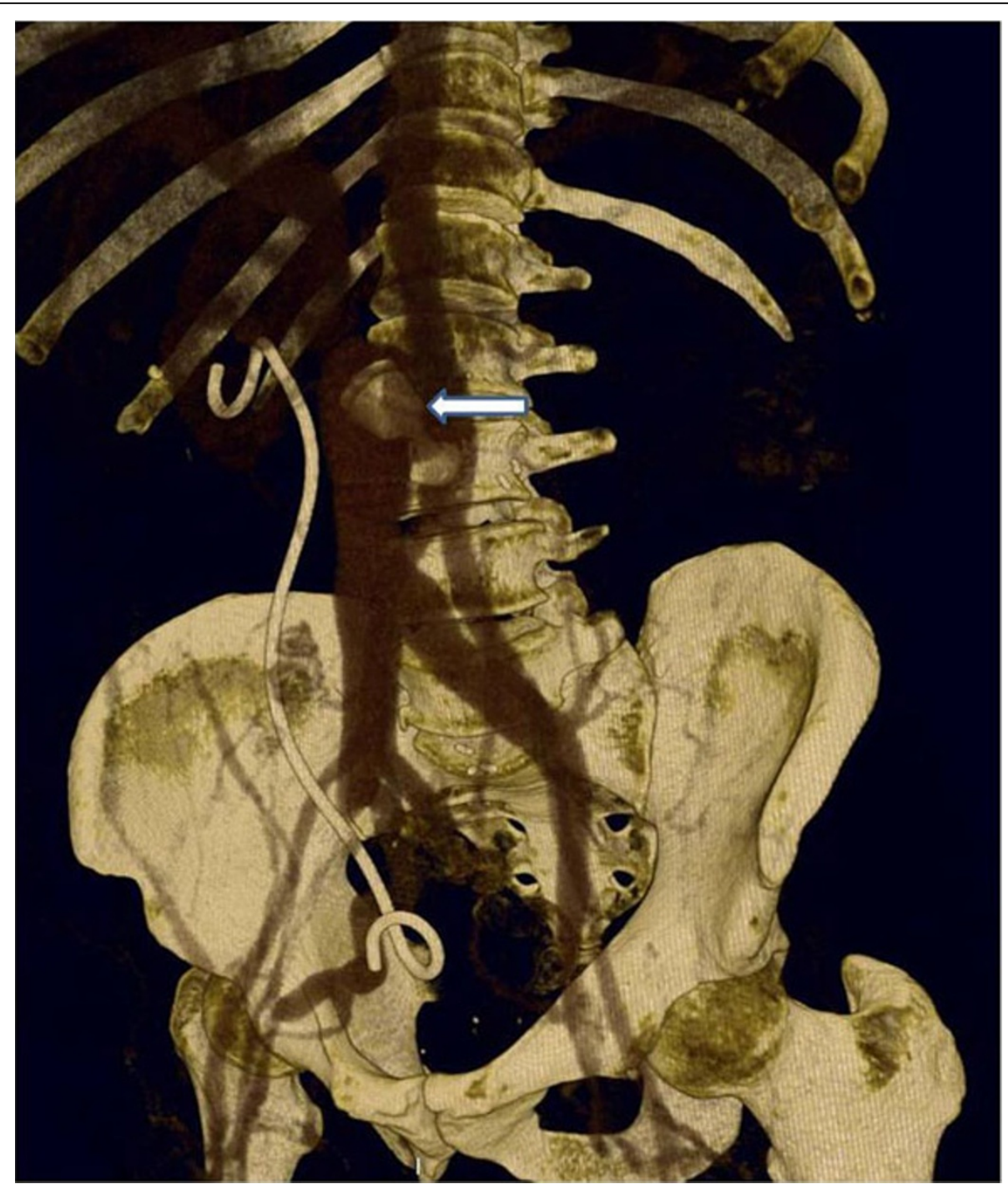

Figure 2 The CT scan at 1 month follow-up after vascular plug implantation showed recurrence of the aorto-caval communication. The Amplatzer vascular plug, still in correct position, was not able to halt the fistulous communication.

complete restoration of the functional capacity (from NYHA class III to NYHA class I) associated to a complete resolution of the lower extremities oedema. The patient also initiated a specific therapy for retroperitoneal fibrosis with steroids and tamoxifen. The CT scan performed one month later showed a complete abolishment of the shunt with no opacization of the inferior vena cava from the abdominal aorta (Figure 3). The Amplatzer vascular plug was excluded from the blood flow after the endoprosthesis implantation (Figure 3).

\section{Conclusion}

Idiopathic retroperitoneal fibrosis (IRPF) is a syndrome of unknown cause that typically presents with constitutional symptoms and back or abdominal pain. Ureteral obstruction is present in as many as $80 \%$ to $100 \%$ of reported cases. However, intestinal or bilary-pancreatic [6-8] or magnetic resonance imaging often shows periaortic soft tissue accumulation that encases the distal aorta below the renal arteries, as well as nearby structures [9-13].

The initial approach often requires surgical, urological, or medical intervention to address anatomic complications. For instance, ureteral obstruction usually respond to stent placement, bowel obstruction requires evaluation, observation and even diversion. However, when these complications have been addressed, medical treatment can be devised to treat the acute inflammation and suppress what appears to be a more chronic immunologic process with subsequent fibrosis.

In the present case, the previous surgical interventions had caused a hyatrogenic aorto-caval communication in 


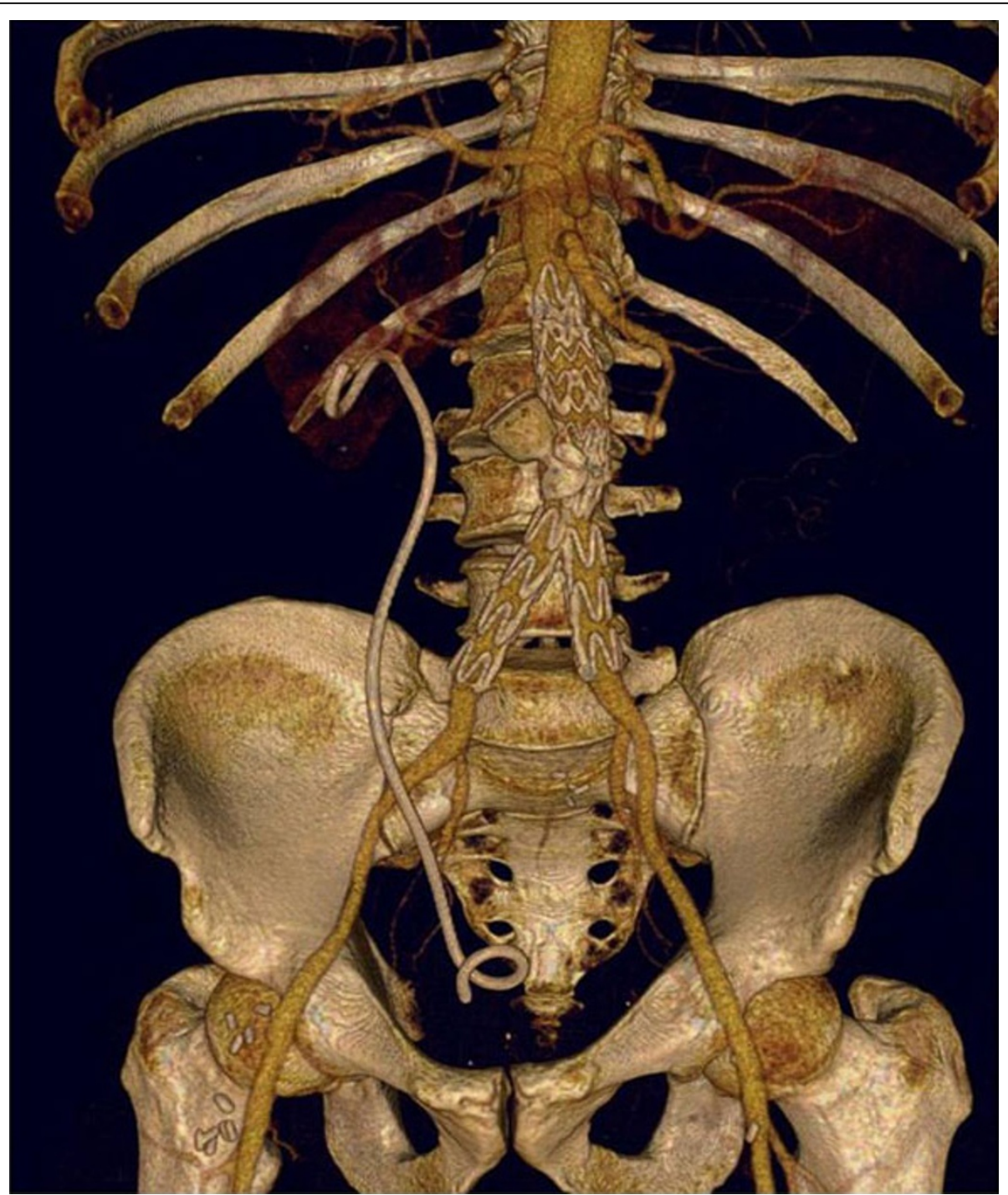

Figure 3 The CT scan 1 month after aortic endoprosthesis implantation showed a complete abolishment of the shunt with no opacization of the inferior vena cava from the abdominal aorta. The Amplatzer vascular plug was excluded from the aortic blood flow after the endoprosthesis implantation.

a patient that had developed a very hostile abdomen to be treated with an additional surgical approach. Since the fistulous shunt was causing very important and life threatening symptoms, we decided to percutaneously intervene before starting an appropriate medical therapy. In fact, any kind of intervention for IRPF does not reduce long term prognosis if not associated to specific pharmacological therapy.

We first decided to close the abnormal communication by using a less invasive approach implanting an endovascular plug usually dedicated to vessel embolization. Previous experience have been reported treating aorto-caval fistulas with vascular plug implantation. However, the few cases reported in the literature refer to either fistulous communication resulting from a surgical intervention for aortic aneurysm or congenital aorto-caval fistula $[3,14,15]$. The present case was complicated from the presence of IRPF which would probably have caused multiple and complicated abnormal communication.

In fact, although the result was initially encouraging, the unfortunate recurrence of an important shunt aggravating the symptoms led us to consider an aortic endoprosthesis to definitely treat the inferior vena cava volume overload [16]. Aortic endoprosthesis have been successfully used to close aorto-caval communication in patients with either ruptured or dissected aortic aneurysm or penetrating abdominal trauma [2,17-21]. 
Aortic endoprosthesis implantation in the present case successfully treated the abnormal shunt resolving both lower extremities oedema and dyspnoea.

This is the first demonstration that such a percutaneous approach can be successfully used to treat a very complicated case of aorto-caval fistula with a device that is commonly used to treat aortic aneurysms.

\section{Acknowledgements}

This article has been published as part of BMC Surgery Volume 12 Supplement 1, 2012: Selected articles from the XXV National Congress of the Italian Society of Geriatric Surgery. The full contents of the supplement are available online at http://www.biomedcentral.com/bmcsurg/supplements/12/S1.

\section{Author details}

${ }^{1}$ Department of Clinical Medicine, Cardiovascular and Immunological Sciences, Federico II University of Naples, Italy. ${ }^{2}$ Department of General, Geriatric, Oncologic Surgery and Advanced Technologies, University

"Federico II" of Naples, Italy.

\section{Competing interests}

The authors declare that they have no competing interests.

Published: 15 November 2012

\section{References}

1. Alexander JJ, Imbembo AL: Aorta-vena cava fistula. Surgery 1989 105(1):1-12.

2. Mitchell ME, McDaniel HB, Rushton FW Jr: Endovascular repair of a chronic aortocaval fistula using a thoracic aortic endoprosthesis. Ann Vasc Surg 2009, 23(1):150-2.

3. Godart F, Haulon S, Houmany M, Francart C, Brevière GM, Rey C, Koussa M: Transcatheter closure of aortocaval fistula with the amplatzer duct occluder. J Endovasc Ther 2005, 12(1):134-7.

4. Umscheid T, Stelter WJ: Endovascular treatment of an aortic aneurysm ruptured into the inferior vena cava. J Endovasc Ther 2000, 7(1):31-5.

5. Vetrhus M, McWilliams R, Tan CK, Brennan J, Gilling-Smith G, Harris P. Endovascular repair of abdominal aortic aneurysms with aortocaval fistula. Eur J Vasc Endovasc Surg 2005, 30(6):640-3.

6. Swartz RD: Idiopathic retroperitoneal fibrosis: a review of the pathogenesis and approaches to treatment. Am J Kidney Dis 2009, 54(3):546-53.

7. Ormond JK: Bilateral ureteral obstruction due to envelopment and compression by an inflammatory retroperitoneal process. J Urol 1948, 59(6):1072-9.

8. Fry AC, Singh S, Gunda SS, Boustead GB, Hanbury DC, McNicholas TA, Farrington K: Successful use of steroids and ureteric stents in 24 patients with idiopathic retroperitoneal fibrosis: a retrospective study. Nephron Clin Pract 2008, 108(3):c213-20.

9. Swartz RD, Lake AM, Roberts WW, Faerber GJ, Wolf JS Jr: Idiopathic retroperitoneal fibrosis: a role for mycophenolate mofetil. Clin Nephrol 2008, 69(4):260-8.

10. Vivas I, Nicolás Al, Velázquez P, Elduayen B, Fernández-Villa T, MartínezCuesta A: Retroperitoneal fibrosis: typical and atypical manifestations. Br J Radiol 2000, 73(866):214-22.

11. Twahirwa N, Rees J: Unusual presentation of idiopathic retroperitoneal fibrosis: case report. East Afr Med J 2008, 85(5):248-52.

12. van Bommel EF, Hendriksz TR, Huiskes AW, Zeegers AG: Brief communication: tamoxifen therapy for nonmalignant retroperitoneal fibrosis. Ann Intern Med 2006, 144(2):101-6.

13. Warnatz K, Keskin AG, Uhl M, Scholz C, Katzenwadel A, Vaith P, Peter HH, Walker UA: Immunosuppressive treatment of chronic periaortitis: a retrospective study of 20 patients with chronic periaortitis and a review of the literature. Ann Rheum Dis 2005, 64(6):828-33.

14. Cil B, Peynircioğlu B, Canyiğit M, Geyik S, Ciftçi T: Peripheral vascular applications of the Amplatzer vascular plug. Diagn Interv Radiol 2008, 14(1):35-9.
15. Abdel Aal AK, Hamed MF, Biosca RF, Saddekni S, Raghuram K: Occlusion time for Amplatzer vascular plug in the management of pulmonary arteriovenous malformations. AJR Am J Roentgenol 2009, 192(3):793-9.

16. Beveridge CJ, Pleass HC, Chamberlain J, Wyatt MG, Rose JD: Aortoiliac aneurysm with arteriocaval fistula treated by a bifurcated endovascular stent-graft. Cardiovasc Intervent Radiol 1998, 21(3):244-6.

17. Takaseya T, Hiromatsu S, Akashi H, Okazaki T, Tobinaga S, Aoyagi S: A case of unilateral leg edema due to abdominal aortic aneurysm with aortocaval fistula. Ann Thorac Cardiovasc Surg 2007, 13(2):135-8.

18. Iannelli G, Di Tommaso L, Cirillo P, Smimmo R, Piscione F, Vosa C: Treatment of residual type $A$ aortic dissection with implantation of the Djumbodis system:is purely endovascular treatment becoming a reality? J Endovasc Ther 2011, 18(3):368-73.

19. lannelli G, Piscione F, Di Tommaso L, Monaco M, Chiariello M, Spampinato N: Thoracic aortic emergencies: impact of endovascular surgery. Ann Thorac Surg 2004, 77(2):591-6.

20. Romano M, Amato B, Markaboui K, Tamburrini O, Salvatore M: Follow-up of patients with previous vascular interventions: Role of multidetector row computed tomographic angiography of the abdominal aorta and lower extremities. J Cardiovasc Surg (Torino) 2004, 45:89-91.

21. Romano M, Mainenti PP, Imbriaco M, Amato B, Markabaoui K, Tamburrini O, Salvatore M: Multidetector row CT angiography of the abdominal aorta and lower extremities in patients with peripheral arterial occlusive disease: Diagnostic accuracy and interobserver agreement. Eur J Radiol 2004, 50:303-308.

doi:10.1186/1471-2482-12-S1-S32

Cite this article as: Rapacciuolo et al:: Percutaneous treatment of a aorto-caval fistula in a old high risk patient. BMC Surgery 2012 12(Suppl 1):S32.

\section{Submit your next manuscript to BioMed Central and take full advantage of:}

- Convenient online submission

- Thorough peer review

- No space constraints or color figure charges

- Immediate publication on acceptance

- Inclusion in PubMed, CAS, Scopus and Google Scholar

- Research which is freely available for redistribution
C Biomed Central 